\title{
Toxicological effect of formalin as food preservative on kidney and liver tissues in mice model
}

\author{
M. A. A. Mamun ${ }^{1}$ M. A. Rahman ${ }^{2}$, M. K.zaman ${ }^{1}$, Z. Ferdousi ${ }^{1}$ and \\ M. Abu Reza* \\ ${ }^{I}$ (Protein Science Lab, Department of Genetic Engineering and Biotechnology, University of Rajshahi, Rajshahi \\ 6205, Bangladesh) \\ ${ }_{2}^{2}$ (Entomology lab, Department of Genetic Engineering and Biotechnology, University of Rajshahi, Rajshahi \\ 6205, Bangladesh)
}

\begin{abstract}
In recent days, use of formalin has alarmingly increased in Bangladesh specifically in fishes, fruits and many other food items, exposing the large majority of the population to severe health risk. The current study was undertaken to evaluate the extent of damage caused by formalin on the kidney and liver tissues in model animal. Twenty four adult mice were divided into two groups as control and treatment. The animals of three treatment groups were given with $10 \mathrm{gm} /$ mouse normal poultry food having following quantity of formalin as $30 \mu \mathrm{l}, 3 \mu \mathrm{l}$ and $0.3 \mu \mathrm{l}(4.2 \mathrm{mg} / \mathrm{kg}, 0.42 \mathrm{mg} / \mathrm{kg}$ and $0.042 \mathrm{mg} / \mathrm{kg}$ body) respectively. After ending the treatment period of 30 days the animals were sacrificed for histological study and visualized under light microscope. Results from the histopathological examination showed large cell deformity including shrieked and ruptured glomeruli, leucocytic infiltrations, degenerated tissue and congestion of renal glomerulus along with hemorrhage in renal tissue and congestion of central vain, enlargement in the sinusoids, deleterious degenerations, mild hemorrhages and coagulation were also observed in hepatic tissue compared with the compact organization of their control. Therefore, we strongly recommend here for the ban of formalin to the common user and current law should be strengthening enough to discourage the use of formalin in food material.
\end{abstract}

Keywords: Formalin, histological effect, kidney, liver, microtome and Mus musculus.

\section{Introduction}

Formalin is a cadaverous chemical [1] of 37-50 percent aqueous solution of dissolved formaldehyde $(\mathrm{CH} 2 \mathrm{O})$ in water. It is flammable, highly reactive with many substances and readily polymerizing colorless gas at normal temperature and pressure [2], [3]. In air, it is readily broken down by sunlight, with a half-life of approximately 30-50 minutes (WHO 1999).But in liquid form, it is stable over time [2], [4].Upon intraperitoneal, oral, or inhaler exposure, formalin quickly diffuses into many tissues, including the brain, testis, and liver[5].Formaldehyde is quickly absorbed from the gastrointestinal tract following ingestion and from the respiratory tract following inhalation which makes it a dangerous chemical to be used as preservative [3], [6]. However, it is inadequately absorbed following dermal contact. Its main routs of exposure in our environment are air (through occupational exposure like as formaldehyde and resin production), smoking (receiving about $0.38 \mathrm{mg} /$ day)[7], dermal exposure[8], [9] and also through water. Formalin can also be administered through food and drinking water naturally and artificially when used as food preservative [10], [11].Annual production of this hazardous chemical varied from 6.4 to 8.1 billion pounds per years "between" 1991-1995 in the U.S [3]. In addition to its abundant uses (such as pressed wood products, paper, textile fibers, adhesives and plastics, carpeting, foam insulation, cosmetics, nail hardeners, disinfectant, some finger paints, and some cleaning products) [2], [3]in our practical life, it is illegally used to preserve various kinds of food stuffs [12], [13].It can prolong the shelf-life of food by protecting against deterioration caused by microorganisms[10].Some dishonest traders have used formalin in the perishable foods to prevent from its decay. Bangladesh is a tropical country with hot and humid weather which tends to quickly decay fruits, vegetables, fishes, meat and other perishable food materials. There are reports that, currently formalin is being used widely and illegally in fishes to keep it fresh, vegetables (tomato and cucumber), fruits (apple and grapes) milk, drinks, sweetmeat, ice-cream and spices (The Daily Star, Sunday, June 08, 2014). In recent times though penalties (5 years imprisonment or Tk 5 lack or both for persons guilty of food adulteration), it seems not enough to control food adulteration in market (The Daily Star, Tuesday, September 10, 2013). In recent times it is being extensively used as food preservative in Bangladesh due to its keen price and comparatively easy to use. Above fact is inspiring the fishermen for preferring formalin rather than ice block. Fruits, vegetables and fishes are the most common food items that are the major target of the dishonest food vendors and merchants [14].As a matter of fact, now a day's formalin may be found in almost all kind of foods, though this chemical has been band for using as food preservative in many countries. Several studies on range experimental animals (exposure with formaldehyde) demonstrated a wide 
number of toxicological effects including histopathological alteration in the stomach (i.e., gastrointestinal lesions (such as papillomata's hyperplasia and hyperkeratosis,), allergy [15], asthma [16], abdominal pain and vomiting. Formalin is significantly related with cancer particularly nasopharyngeal cancer in humans through inhalation during occupational exposure [17] and sometimes caused gastrointestinal cancer when administered with drinking water with high concentration [18].It also facilitates DNA-protein crosslink mainly in the anterior regions of the nasal tissue through inhaled exposure in rodent animal [19], [20]. Due to abundant use of formalin in different food items and consumption of the foods contaminated with this dangerous chemical, a huge number of populations particularly the kids and the elderly are exposing themselves everyday to severe health hazard in Bangladesh and some other developing countries [21], [22].Therefore, the current project was undertaken to estimate the degree of injury of kidney and liver caused by consumption of foods containing with formalin.

\subsection{Experimental Animals:}

\section{Materials and methods}

Twelve matured male albino mice weighing around 23-27gm (80-90 days old) were purchased from the Department of Pharmacy of the University of Jahangirnagar, Dhaka, Bangladesh. Mice were kept in plastic mice cages for about 15 days to acclimatized in the trial room environment, having temperature of $24 \pm 1^{\circ} \mathrm{C}$, controlled humidity situation $(65 \%)$ and 12:12 hour light dark cycle. Animals were feed with poultry food $(10 \mathrm{gm} /$ day/mouse $)$ and water. All mice were handled in accordance with the typical guide for care and use of laboratory animals (under the license of Institutional animal, medical ethics, bio-safety and bio-security committee (IAMEBBC) for experimentations on animal, human, microbes and living natural sources . No. 33/320/IAMEBBC/IBSC).

\subsection{Chemical:}

Formalin (37\%) was procured from open market of shaheb bazer in Rajshahi by the trade name of formalin and produced by Brothers chemical, China. The concentration cypermethrin of was calculated from the percentage of active ingredient of commercial formulation of cypermethrin.

\subsection{Experimental design:}

Twenty four matured female switch albino mice were randomly distributed into two groups, as control and treatment.

2.3.1. Control group: The animals of this group were feed with $10 \mathrm{gm} / \mathrm{mouse}$ (total $60 \mathrm{gm}$ for six animals) without any additive in their food. Plenty of water was supplied using feeding bottle.

2.3.2. Treatment groups: There were three treatment groups containing six animals in each group.

- Group 1: Experimental animals were orally introduced with formalin at a dose level of $4.2 \mathrm{mg} / \mathrm{kg}$ body weight for a period of 30 days.

- Group 2: Experimental animals were orally administered with formalin at a dose level of $0.42 \mathrm{mg} / \mathrm{kg}$ body weight for a period of 30 days.

- Group 3: Experimental animals were orally introduced with formalin at a dose level of $0.042 \mathrm{mg} / \mathrm{kg}$ body weight for a period of 30 days.

\subsection{Preparation of histological slide:}

After completion of treatment period, the animals were anesthetized using chloroform and sacrificed by cervical dislocation. Liver and kidney was collected carefully from the mice using standard procedure. Collected organs were washed thoroughly with $0.9 \%$ normal saline to remove any race of blood. Fat tissues adhered to the organs were also removed carefully and afterwards organs were sliced into small tissue pieces using a surgical scalpel for allowing easy penetration of the chemicals inside the tissue. The dissected tissue was treated with Bouin's fluid (fixative) for -16-18 hour and subsequently washed under running tap water for one hour until complete removal of most of the Bouin's fluid from the tissues. Followed by washing, dehydration of the tissues was conducted by immersing the tissue in a series of gradually increasing concentrations of alcohol $(50 \%, 70 \%$, $80 \%, 95 \%$ and absolute alcohol) and embedded into paraffin wax for making blocks. The block was to be trimmed by removing of wax from the surface of block to expose the tissue. Sectioning of the tissue was performed by using a microtome (The microtome machine was sold from Tokyo, Japan by the trade name of SHIBUYA produced by optical. Co LTD). The microtome was pre-set to cut the tissue as thicknesses around 6 $\mu \mathrm{m}$. Blocks Small ribbons of tissue sections were placed on microscopic slide with help of warm distil water containing few drops of Mayer's albumen and deparaffinized with xylene solution. Haematoxylene and eosin yellow solution was used to stain the tissue for preparing permanent slide. Histopathological changes were 
observed under 20x of a light microscope (The microscope was purchased from Italy by the trade name optika) and snaps were taken.

\subsection{Effect of formalin on mice kidney:}

\section{Result}

In our experimental model, the microtome sections of kidney tissues of control mice showed regular structure with well distributed glomerulus and related tubules (Fig.1A). However, in case of formalin treated kidney, large cell gross change in the histology was observed. Glomeruli was found to be shrieked and ruptured, leucocytic infiltrations in renal tubules, degenerated tissue and congestion of renal glomerulus along with hemorrhage were noticed in case of treatment group1 (Fig. 1B). The slides from treatment group2 showed shrieked and ruptured glomerulus and leucocytic infiltrations in renal tubules (Fig.1C). Moreover, no significant histopathological changes without mild congestion were observed in renal tissueof treatment group 3 (fig $1 \mathrm{D}$ ). These findings clearly indicated that formalin causes damage to kidney in the concentration used in the current experiment.

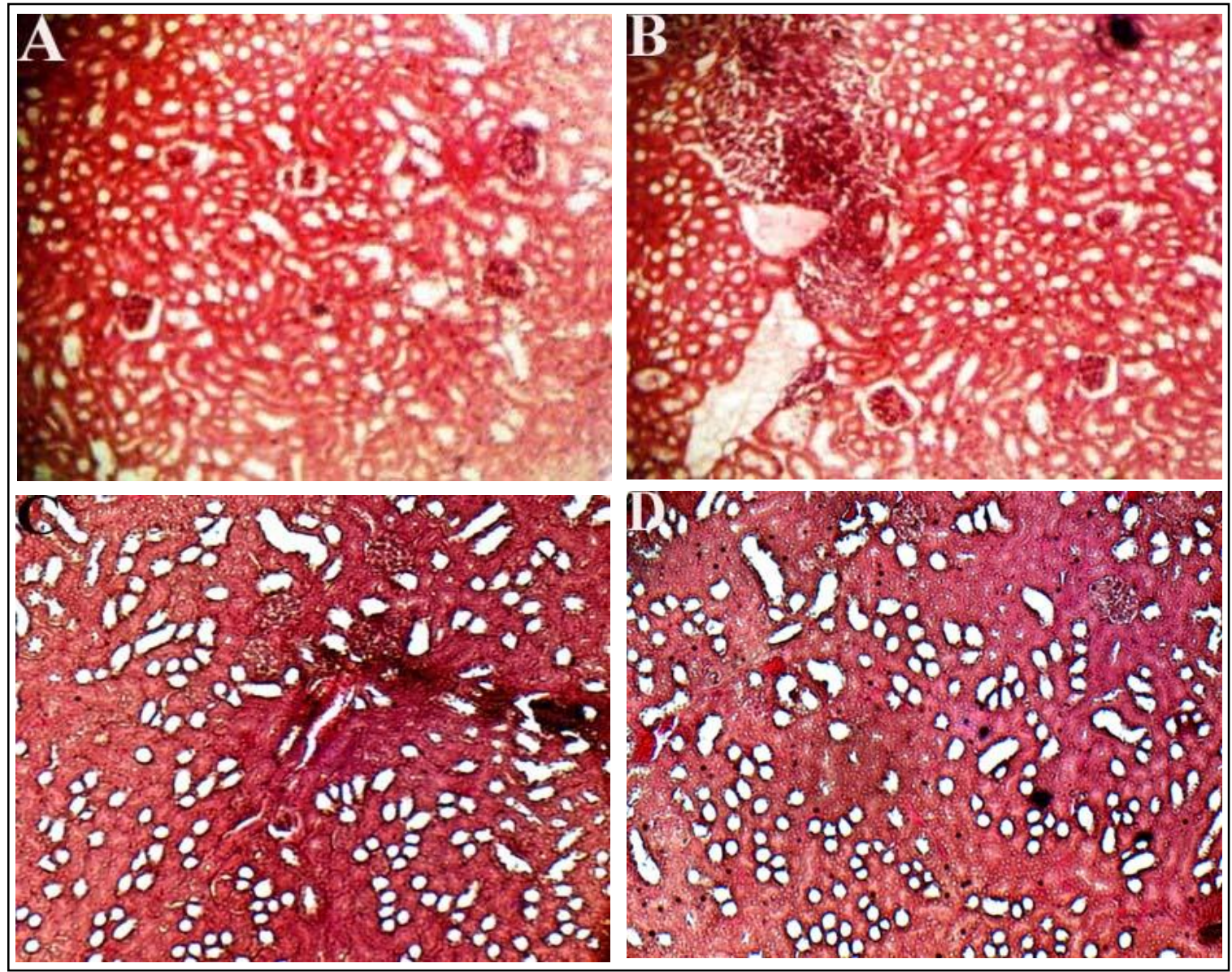

Figure 1: Renal histoarchitecture of switch albino mice. (A) Compact configuration of renal tissue of control mice. (B) Shrieked and ruptured glomeruli along with hemorrhage of treatment group 1. (C) Leucocytic infiltrations and shrieked glomeruli of treatment group 2. (D) Mild congestion was observed in renal tissueof treatment group 3 .

\subsection{Effect of formalin on mice liver:}

Similarly, the microtome sections of the liver of the control mice showed regular and compact configuration with well hepatic cell, sinusoid and associated vain and capillaries (Fig. 2A). However, liver sections of treated mice showed some severe histological alterations. Congestion in the central vain, (this results in dilatation of central veins and pooling of blood in the sinusoids towards the center of the liver lobule), deleterious degenerations in tissues, enlargement in the sinusoids, mild hemorrhages inside the tissue and reduced compactness of the cells by the formation of intercellular spaces were observed in case of treatment group1 (Fig.2B). The slides from treatment group2 showed mild congestion in central vain (Fig.2C). Moreover, 
no significant hepatic changes without moderate enlargment of sinusoid were observed in renal tissue of treatment group 3 (fig $2 \mathrm{D}$ ).

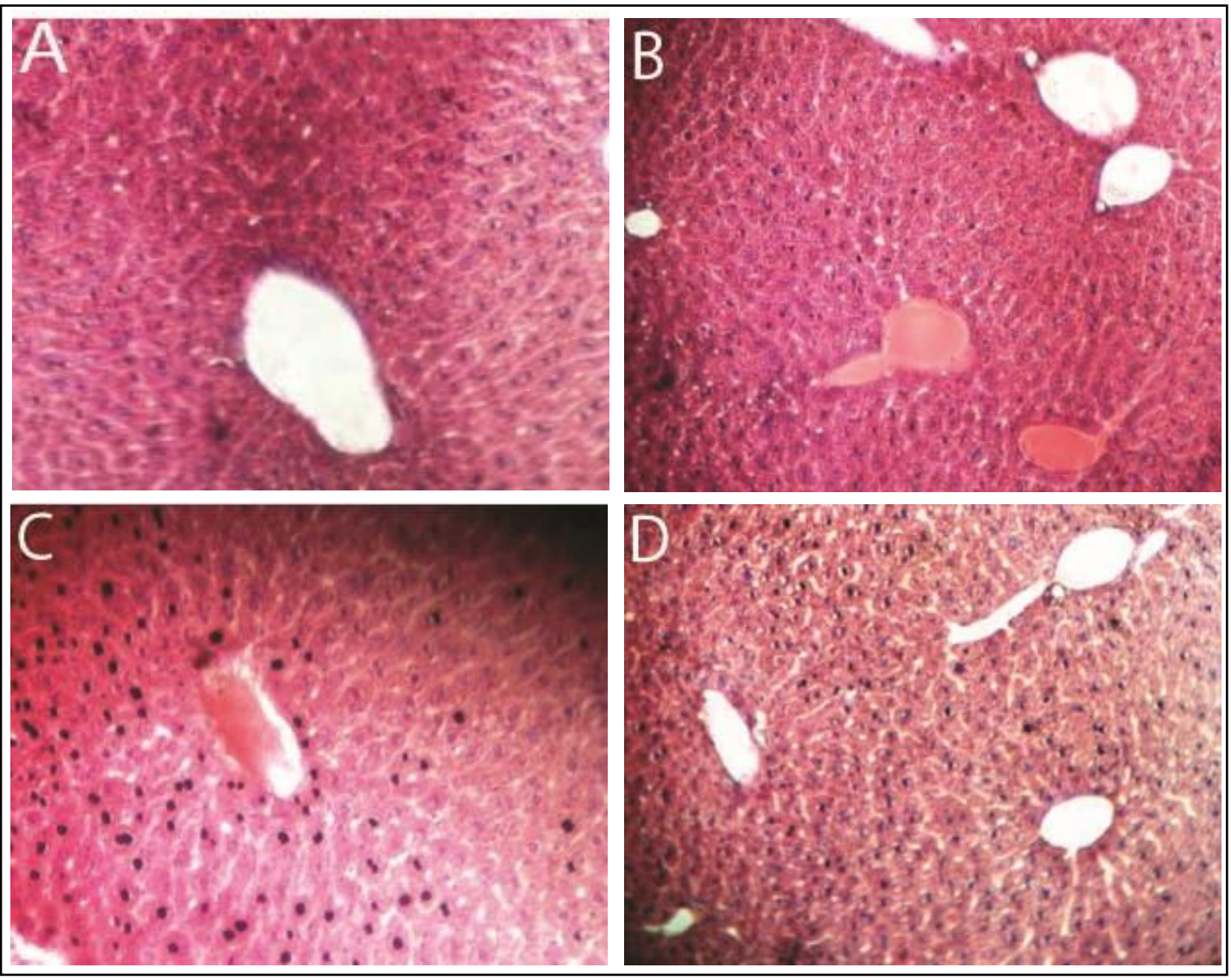

Figure 2: Hepatic organization of switch albino mice. (A) Compact configuration of renal tissue of control mice. (B) Congestion of central vain and mild hemorrhages inside the tissue of treatment group 1. (C) Mild congestion in central of treatment group 2 (D). Moderate enlargment of sinusoid of treatment group 3.

\section{Discussion}

Sufficient study by different workers has already been done on different animal (Cymolgus monkeys, rats, Syrian golden and hamsters etc) about the harmful effect of this culprit chemical through inhalation and dermal exposure and showed irritation of the eyes, nose, and throat, headaches, skin sensitization, dermatitis, hoarseness, congestion, and nasal squamous cell metaplasia [23].However, histological data on the effects of formalin on liver and kidney tissue through oral administration till was not enough available[24].In the present study, the animals were orally administered formalin with normal food for one month and the microscopic slide from selected organs showed prominent histological changes in their liver and kidney tissues. Here Formaldehyde was used orally as a dose of tenfold dilution of LD50 (42mg/kg) body weight for treatment group 1 and 10 times dilution for the rest of the two groups respectively. Any noticeable disorder of experimental animals has not been observed during exposure period without small intake of food and dull appearance. Histology of kidney tissue of treated animal showed degenerated and shrinkage tissue with ruptured and deformed glomerulus. Whereas the section of liver tissue of treated mice samples showed severe histopathological alterations. Earlier studies on carcinogenicity demonstrated that formaldehyde is a nasal carcinogen in rats and although data are limited in mice and no tumors were observed in hamsters [25]. However, we did not observe any tumor in liver, kidney or any other organ. Some work of formalin through drinking water and food stuff on stomach and other tissue of mice, dogs and rat demonstrated little effect except for mild pharyngeal and gastric discomfort, significant increase in the thickness of the stomach lining epithelium [26] and irritation in mucus membrane, but such harmful effect was also alleviated' by diluting the formaldehyde prior to ingestion [27], [28].Inflammatory lesions in digestive system following oral administration formaldehyde has been reported in claves [29] and rats [30], [31], [32].The current observation showed that nature and intensity of histological alteration exposure through oral introduction of formalin are dose and time 
dependent.

\section{Conclusion}

Current study suggested that the use of formalin is injurious to health and causes serious effect on liver and kidney of mice model, if they are consumed regularly. Therefore, strict law needs to be formulated to prevent such unlawful act of adding formalin to the food staff and it should also have to be reflected in our national health policy. Besides, making new laws the law enforcement agencies of Bangladesh should be more vigilant for proper implementation of the law. Everybody should wash vegetables and fruits properly before consuming to allay harmful effect of formalin and searching out safe food preservative other then formalin for preventing foods from spoiling.

\section{Acknowledgement:}

I would like to acknowledge ministry of science and technology of Bangladesh for financial support.

\section{Reference}

[1]. S. kawamata, H Kodera, Reduction of formaldehyde concentrations in the air and cadaveric tissues by ammonium carbonate, Anatomical Science International,79, 2004, 152-157.

[2]. World Health Organization (WHO). IARC Monographs on the Evaluation of Carcinogenic Risks to Humans. 2006. Volume 88 Formaldehyde, 2-Butoxyethanol and 1-tert-Butoxy-2-propanol.

[3]. Agency for Toxic Substances and Disease Registry (ATSDR). Toxicological Profile for Formaldehyde. US department of Health and Human Services 1999. Atlanta, US.

[4]. World Health Organization. International Program on Chemical Safety, Environmental Health. 1999. Criteria 89: Formaldehyde.

[5]. Smith AE, Formaldehyde, Occup Med, 42, 1992, 83-8.

[6]. International Programme on Chemical Safety (IPCS). Formaldehyde. Environmental Health Criteria 89. 1989. WHO. Geneva.

[7]. US NRC. Formaldehyde: an assessment of its health effects.1980.Washington, DC.

[8]. F. Lindskov, Contact urticaria to formaldehyde, Contact dermatitis, 8, 1982,: 333-334

[9]. Takahashi S, Tsuji K, Fujii K, Okazaki F, Takigawa T, Ohtsuka A, Iwatsuki K, Prospective study of clinical symptoms and skin test reactions in medical students exposed to formaldehyde gas. J Dermatol,34, 2007, 283-289.

[10]. Restani P, Restelli AR, Galli CL, Formaldehyde and hexamethylenetetramine as food additives: chemical interactions and toxicology. Food additives and contaminants, 9, 1992, 597-605.

[11]. Tomkins BA, McMahon JM, Caldwell WM, Wilson DL, Liquid chromatographic determination of total formaldehyde in drinking water. Journal of the Association of Official Analytical Chemists, 72, 1989, 835-839.

[12]. Kusumawati F, Trisharyanti IDK, Finding the content of formalin which is used for preserving wet noodle in traditional markets of Surakarta. Jurnal Penelitian Sains \& Teknologi, 5, 2004, 131-140.

[13]. Kollu NR, Baireddy VR, Sivadevuni G, Solipuram MR. Influence of volatile compounds and food preservatives in the management of fumonisins (B1) production by Fusarium moniliforme. African Journal of Biotechnology, 8, 2009, 4207-4210.

[14]. Tang X, Bai Y, Duong A, Smith MT, Li L, Zhang L, Formaldehyde in China: Production, consumption, exposure levels, and health effects.Environment International, 35, 2009, 1215-16.

[15]. Griesemer RA, Ulsamer AG, Acros JC, Report of the federal panel on formaldehyde. Environ Health Perspect, 43, 1982, $139-168$.

[16]. Rumchev KB, Spickett JT, Bulsara MK, Phillips MR, Stick SM.Domestic exposure to formaldehyde significantly increases the risk of asthma in young children. Eur.Respir.J,20, 2002, 403-408.

[17]. Hayes RB, Raatgever JW, De Bruyn A, Gerin M. Cancer of the nasal cavity and paranasal sinuses, and formaldehyde exposure. Int J Cancer, 37, 1986, 487-492.

[18]. Takahashi M, Hasegawa R, Furukawa F, Toyoda K, Sato H, Hayashi Y.Effects of ethanol, potassium metabisulfite, formaldehyde and hydrogen peroxide on gastric carcinogenesis in rats after initiation with N-methyl-N'-nitro-N-nitrosoguanidine. Japanese Journal of Cancer Research (Gann), 77, 1986, 118-124.

[19]. International Agency for the Research on Cancer (IARC), Formaldehyde, 88, 2004, IARC. Lyon.

[20]. Casanova M, Morgan KT, Steinhagen WH, Everitt JI, Popp JA, Heck HD, Covalent binding of inhaled formaldehyde to DNA in the respiratory tract of Rhesus monkeys: Pharmacokinetics, rat-to-monkey interspecies scaling, and extrapolation to man. Fundam Appl Toxicol, 17, 1991, 409-428.

[21]. Smedje G, NorbackD, Incidence of asthma diagnosis and self-reported allergy in relation to the school environment--a four-year follow-up study in schoolchildren. Int.J.Tuberc.Lung Dis, 5, 2001, 1059-1066.

[22]. Franklin P, Dingle P, Stick S, Raised exhaled nitric oxide in healthy children is associated with domestic formaldehyde levels.Am.J.Respir.Crit Care Med, 161, 2000, 1757-1759.

[23]. Rusch G, MClary JJ, Rinehart WE, Bolte HF, A 26-week inhalation toxicity study with formaldehyde in monkey, rat. And hamster. Toxicol. Appl. Pharmacol, 68, 1983, 329-343.

[24]. Restni P, Galli CL, Oral toxicity of formaldehyde and its derivatives. Critical .Rev. in Toxicol, 21, 1991, 315-328

[25]. Swenberg JA, Kerns WD, Mitchell RI, Gralla EJ, Pavkov KL,Induction of squamous cell carcinomas of the rat nasal cavity by inhalation exposure to formaldehyde vapor. Cancer Research, 40, 1980, 3398-3402.

[26]. Shehab, Amal A.; Mahdy, Amal A, Effects of oral administration of formaldehyde on albino rat stomach: light and scanning electron microscopic study. Egyptian Journal of Histology, 34, 2011, 662-673.

[27]. Yonkman FF, Lehman AT, pfiffer CC, Chase HF. A study the possible toxic effects of prolonged formaldehyde ingestion. J. Pharmacol. Exp. Ther,72, 1941, 46.

[28]. Johanson FR, Levinsks GJ, Tegeirs AS, Effect formaldehyde in the rat and dog following oral exposure. Toxicol. Letters, 30, 1986, $1-6$.

[29]. Preston TR, Rattray E, White F, Effect of feeding formalin-treated skim milk to claves. Anim Prod, 2, 1960, 33 -36.

[30]. Til HP, Woutersen RA, Feron Vj, Hollanders VH, Falke HE, Clary JJ. Two- year drinking- water study in rats, Food chem. Toxicol, 27, 1989, 77-87.

[31]. Tobe, Naito MK, KurokawaY. Chronic toxicity study on formaldehyde administered orally to rats. Toxicol, 56, 1989, 79-86.

[32]. Til HP, Woutersen RA, Feron VJ, Clary JJ, Evaluation of oral toxicity of acetaldehyde and formaldehyde in four week drinkingwater study in rats, Food chem. Toxicol, 26, 1988, 447-452. 